\title{
Increased EPA levels in serum phospholipids of humans after four weeks daily ingestion of one portion chicken fed linseed and rapeseed oil
}

\author{
Anna Haug ${ }^{1 *}$, Nicole F Nyquist ${ }^{1}$, Therese J Mosti ${ }^{1}$, Malin Andersen ${ }^{1}$ and Arne T Høstmark ${ }^{2}$
}

\begin{abstract}
Since the amounts of arachidonic acid (AA) and EPA in food may have implications for human health, we investigated whether a small change in chicken feed influenced the blood lipid concentration in humans ingesting the chicken. Forty-six young healthy volunteers (age 20-29) were randomly allocated into two groups in a double-blind dietary intervention trial, involving ingestion of about $160 \mathrm{~g}$ chicken meat per day for 4 weeks. The ingested meat was either from chickens given a feed concentrate resembling the commercial chicken feed, containing $4 \%$ soybean oil (SO), or the meat was from chickens given a feed where the soybean oil had been replaced by $2 \%$ rapeseed oil plus $2 \%$ linseed oil (RLO).

Serum total cholesterol, LDL and HDL cholesterol, triacylglycerols, serum phospholipid fatty acid concentration, blood pressure, body weight and C-reactive protein were determined at baseline and post-intervention. In subjects consuming chicken meat from the RLO group there was a significantly $(p<0.001)$ increased concentration of EPA in serum phospholipids, and a reduced ratio between AA and EPA. The participants that had a low\% of EPA + DHA in serum phospholipids (less than 4.6\%), all increased their\% of EPA + DHA after the four week intervention period when consuming the RLO chicken. No significant response differences in cholesterol, triacylglycerol, C-reactive protein, body weight or blood pressure were observed between the groups. This trial demonstrates that a simple change in chicken feed can have beneficial effects on amount of EPA and the AA/EPA ratio in human serum phospholipids.
\end{abstract}

Keywords: n-3 fatty acids, Serum phospholipids, EPA, Arachidonic acid, Chicken meat, Feed, Linseed oil, Rapeseed oil, Soybean oil

\section{Background}

Chicken meat is popular to eat, and it is regarded as a healthy type of meat [1]. In Norway poultry meat accounts for about $25 \%$ of the total meat intake $[2,3]$, and the consumption of this type of meat has shown an increasing trend. Meat is one of the food items that are good carriers of long chain polyunsaturated fatty acids (LC PUFAs). The fatty acid composition of chicken meat is affected by the type of fat in the chicken feed. Commercial chicken feed is based on grains and soybean oil rich in $\mathrm{n}-6$ fatty acids and the ratio of $\mathrm{n}-6$ to $\mathrm{n}-3$ in the feed is about 10-15/1. The potential of chickens to convert the $n-6$ and n-3 feed fatty acids to the

\footnotetext{
*Correspondence: anna.haug@umb.no

'Department of Animal and Aquacultural Sciences, The Norwegian University of Life Sciences, P.O.BOX 5003, Ås 1432, Norway

Full list of author information is available at the end of the article
}

respective long chain $n-6$ and $n-3$ fatty acids has been studied intensively, showing that the concentration of $n-6$ linoleic acid, (LA) and n-3 alpha-linolenic acid, (ALA) fatty acids in the feed influence the production of the long $n-6$ and $n-3$ fatty acids, such as arachidonic acid (AA), eicosapentaenoic acid (EPA), docosapentaenoic acid (DPA) and docosahexaenoic acid (DHA) in the chicken $[4,5]$.

The n-6 and n-3 fatty acids compete for binding to enzymes, receptors and membranes affecting cell metabolism. Overproduction or imbalance (e.g. between thromboxanes and prostacyclins) of the different eicosanoids are implicated in the pathogenesis, symptom severity or rate of progression of several common chronic diseases, such as allergy, cardiac diseases, cancer, pain, rheumatoid arthritis, other inflammation and high blood pressure [6-12]. DHA has, moreover, an 
important structural role as a major component in membrane lipids in the brain, retina, testicles and spermatozoa. The reasons for this are not well understood, but it has been suggested that it is mainly for improving membrane fluidity in the mitochondria, thus facilitating electron transport through the respiratory chain and reducing the ratio between rates of mitochondrial production of reactive oxygen species (ROS) and ATP [7]. Even though much of the underlying biochemical mechanisms explaining the causal connection between dietary intakes of LC PUFAs, the dietary n-6/ $\mathrm{n}-3$ ratio and eicosanoid biosynthesis and disease processes have been known for more than 40 years, neither the agricultural sector nor preventive medicine seem to have shown much interest in making practical use of the information.

From known physiology, a combination of AA overconsumption and underconsumption of EPA and DHA should lead to enhancement of the death risk both from cardiovascular disease and cancer. Most of the red meat produced in the United States has a high n-6/n-3 ratio, e.g. pork leg (no 10010[13]) has about 25:1, beef (no 23652[13]) has 18:1, and chicken meat (no 05011[13]) has 8:1. However, grass fed beef (no 13000[13]) is shown to have an $n-6 / n-3$ ratio of only $2: 1$. The same low ratio is shown in sheep meat from e.g. Iceland, where grass feeding is commonly practiced, being about 1.8:1[14]. The association between red meat consumption and death risk from cardiovascular disease or cancer in populations who consume large quantities of red meat with a natural fatty acid composition, has not yet been well enough systematically evaluated.

When comparing the intakes of n-6 and n-3 fatty acids in the western diet with the intake in earlier times, it seems to be a higher concentration of n-6 and lower n-3 fatty acid concentration in meat, offal and eggs today (because the $n-6 / n-3$ ratio of the animal diet is now unnaturally high) [6]. The high n-6 content in feeds leads to increased synthesis of AA in the animals, and an increased load of AA for the consumer. A change in the n- 6 and n-3 balance in the animal feed back to more natural concentrations is healthier for the animals, and it is safe. It is also without side effects (which all commonly used pharmacological inhibitors of eicosanoid synthesis do have) and cheaper for the consumers than to take drugs for dampening eicosanoid synthesis. It is technologically easy and relatively inexpensive to produce poultry meat with much more long-chain n-3 fatty acids and less arachidonic acid than now [15]. The health economic benefits of such livestock products for society as a whole may easily outweigh the direct costs for the poultry farming sector. It may be concluded that time is overdue for a better balanced intake of n- 6 and n-3 fatty acids in food.
Practical ways to improve the fatty acid composition of chicken meat to contain less n- 6 and more n-3 may be by excluding soybean oil from the commercial feed, and add rapeseed- and linseed oil instead. The n-6/n-3 ratio in the feed will thereby be reduced considerably, and the ratio in the chicken meat will improve. It has been shown that the ratio between the n- 6 fatty acid AA and the n-3 fatty acid EPA in chicken breast muscle was about 3:1 when adding 4\% rapeseed oil and 1\% linseed oil to the feed [16].

The objective of the present study was to examine the effects of consuming a daily portion of chicken meat for four weeks; either meat from chickens fed a traditional feed supplemented with soybean oil, or feed with linseed- plus rapeseed oil, on the fatty acid composition and the ratio n-6/n-3 and AA/EPA in serum phospholipids, blood lipids, C-reactive protein and blood pressure in healthy 20-29 year old subjects.

\section{Methods}

\section{Study design for human experiment}

Forty-six healthy volunteers, 11 males and 35 females, aged 20 to 29 years were participating in the study. The study lasted for 28 days and was carried out in OctoberNovember 2011. Most of the participants were students at the Norwegian University for Life Science. The majority had normal BMI; individual BMI ranged from 17.5 to 33.5. They were not taking any medications, supplements or fish oil, and not eating fatty fish. The study was double blind and randomized. The participants were randomly allocated into one of two groups: to consume chicken meat from chickens that had been fed a concentrate feed supplemented with soybean oil or with rapeseed plus linseed oil. Some of the participants were living together in student flats, and they were allocated into the same group so they could cook together and eat the same type of chicken. The participants were recruited by two Masters students. The Masters students were not participating in the study themselves, and did not know the type of chicken feed. The participants were asked to continue with their normal dietary habits, and not to be slimming during the experimental period. Every week, two frozen chickens (the weight of a chicken was about $1 \mathrm{~kg}$ ) were given to each participant. The participants were given recipes indicating how to cook the chickens. They told later in the study that they were not aware of how easy it was to cook the whole chickens.

\section{Approval of the study}

This study was conducted according to the guidelines laid down in the Declaration of Helsinki and all procedures involving human subjects were approved by the Regional Committee for Medical Research Ethics and approved by the Norwegian Data Inspectorate. Written 
informed consent was obtained from all the subjects, and they were informed that they could quit the study whenever they wanted without giving any reason.

\section{Blood samples, anthropometric and blood pressure measurements}

At baseline (day 1) and at post-intervention (day 28) the participants were weighed using the same scale (Soehnle Digital personal scale, 467017201, Germany) and blood pressure was measured using an automatic blood pressure monitor approved for medical purposes (UA-767 Plus 30. Blood pressure monitor, A\&D, Japan). The blood pressure was taken three times according to the instruction manual. The height was measured at baseline using a wall mounted stadiometer, for calculation of BMI; weight, kg / (height, m) ${ }^{2}$.

Blood samples were collected from fasting subjects (minimum $12 \mathrm{~h}$ fast) at baseline and post-intervention (between 07.00 and 10.30). The blood samples were left for $0.5-2 \mathrm{~h}$ at room temperature before centrifuging at $1300 \mathrm{~g}$ for 12 minutes. Serum was then frozen and kept at $-20^{\circ} \mathrm{C}$ until analyzed. Blood sampling and measuring of weight, height and blood pressure were done at the local medical health center.

\section{Serum analyses}

Human serum phospholipid fatty acids were determined using the following method; serum was thawed overnight at $4^{\circ} \mathrm{C}$ and vortexed for $5 \mathrm{sec}$. Dichloromethane/methanol were added to $200 \mu \mathrm{l}$ serum and $100 \mu \mathrm{l}$ internal standard (1,2 diheptadecaonyl-sn-glycero-3-phosphatidylcholine). After shaking and centrifugation the supernatants were transferred to new vials and washed in $0.9 \% \mathrm{NaCl}$ solution. Lower phases were transferred to SPE columns. Neutral lipids were washed out with dichloromethane /isopropanol and MTBE/formic acid. Phospholipids were eluted with methanol. After evaporation to dryness in a vacuum centrifuge, phospholipids were transmethylated with sodium metoxide and FAMEs were extracted to hexane before GC analysis. Analysis was performed on a 7890A GC with a split/split less injector, a 7683B automatic liquid sampler, and flame ionization detection (Agilent Technologies, Palo Alto, CA). Separation was performed on a SP $2380(30 \mathrm{~m} \times 0.22 \mathrm{~mm}$ i.d. $\times 0.25 \mu \mathrm{m}$ film thickness $)$ column (Supelco, Inc., Bellefonte, PA).

Determination of serum total cholesterol, HDL cholesterol (HDL), LDL cholesterol (LDL), triacylglycerol (TAG) and CRP was performed using routine laboratory methods (SP 03-05 Avida 2400. Fürst Medical Laboratory, Norway).

\section{The chicken feeding experiment; feed production and chickens}

The animals were cared for according to laws and regulations controlling experiments with live animals in
Norway (The Animal Protection Act of December $20^{\text {th }}$, 1974 and the Animal Protection Ordinance Concerning Experiments with Animals of January $\left.15^{\text {th }}, 1996\right)$.

The two types of chicken feed were produced at the Center for Feed Technology, Ås, Norway. The feed was based on wheat, and the two feed types; SO and RLO, were identical with the exception of supplemented oil, being either $4 \%$ soybean oil or 2\% rapeseed oil (Askim bær- og fruktpresseri, Askim, Norway) plus 2\% linseed oil (Naturata AG, Murr, Germany) (Table 1). The wheat was ground on a hammer mill, $3 \mathrm{~mm}$ sieve and the feed was pelleted with cold pelletation $3 \mathrm{~mm}, 600 \mathrm{~kg} /$ hour. The feed was packed in $500 \mathrm{~kg}$ sacks, and it was produced the same week as the onset of the feeding of the chickens. A small part of the feeds was ground, and this meal was given to the small chickens the first week. After the first week, the chickens were eating feed pellets.

Six hundred newly hatched male broiler chickens (Ross 308, Nortura Samvirkekylling, Norway) were randomly divided into two rooms for chicken production. The floor was covered with wood shavings, and the

Table 1 Chicken feed composition, $\%$ of ingredients

\begin{tabular}{lll}
\hline & SO & RLO \\
\hline Wheat & 45 & 45 \\
\hline Maize gluten & 10 & 10 \\
\hline Soybean meal & 17 & 17 \\
\hline Oat & 15 & 15 \\
\hline Rendered fat & 4 & 4 \\
\hline Soybean oil & 4 & 0 \\
\hline Rape seed oil & 0 & 2 \\
\hline Linseed oil & 0 & 2 \\
\hline Choline cholride & 0.13 & 0.13 \\
\hline Mono calcium phosphate & 1.4 & 1.4 \\
\hline Ground limestone & 1.3 & 1.3 \\
\hline Sodium chloride & 0.25 & 0.25 \\
\hline Sodium bicarbonate & 0.2 & 0.2 \\
\hline Mikromin Fjørfe FK50 & 0.15 & 0.15 \\
\hline Mikromin Selen 300FK & 0.1 & 0.1 \\
\hline Vitamin A & 0.03 & 0.03 \\
\hline Vitamin E & 0.06 & 0.2 \\
\hline Vitamin ADBK & 0.09 & 0.2 \\
\hline Litamin D3 & 0.08 & 0.2 \\
\hline -lysine & 0.2 & $2 \%$ \\
\hline D-threonine & 0.2 & 0.2 \\
\hline
\end{tabular}

The two diets were identical except the content of $4 \%$ soybean oil (SO) or $2 \%$ rapeseed oil plus $2 \%$ linseed oil (RLO).

Composition of Mikromin Fjørfe FK 50 is: $35 \mathrm{~g} \mathrm{Fe} / \mathrm{kg}, 10 \mathrm{~g} \mathrm{Cu} / \mathrm{kg}, 85 \mathrm{~g} \mathrm{Mn} / \mathrm{kg}$, $55 \mathrm{~g} \mathrm{Zn} / \mathrm{kg}$ and $0.7 \mathrm{I} / \mathrm{kg}$. Mikromin Selen $300 \mathrm{FK}$ is: $0.3 \mathrm{~g} \mathrm{Se} / \mathrm{kg}$. Both mixtures are from Normin AS, Hønefoss, Norway. 
chickens had free access to water and feed. The temperature in the two rooms was kept at $32^{\circ} \mathrm{C}$ for the first three days, before being reduced by $0.5^{\circ} \mathrm{C}$ per day until $21^{\circ} \mathrm{C}$ and then kept at this temperature until slaughter at day 32. During the initial $24 \mathrm{~h}$ the chickens were kept in continuous lighting, followed by six days with $23 \mathrm{~h}$ light and one $\mathrm{h}$ darkness. From day seven the lights were turned off for two periods per day; from 1700 to $2100 \mathrm{~h}$, and 0000 to $0400 \mathrm{~h}$. The chickens were inspected by a veterinarian each week. In total 13 birds died during the experiment; eight in the SO dietary treatment group, and five in the RLO dietary treatment group. This gives a total mortality rate of about $2 \%$, which is acceptable. The dead chickens did not undergo post mortem autopsy.

At day 32, the chickens were sent to a commercial abattoir; Nortura kyllingslakteri, Rakkestad, Norway, and were slaughtered according to routine practice. The carcasses were frozen at $-20^{\circ} \mathrm{C}$. Three days later the human dietary intervention study started.

\section{Chicken feed and chicken breast muscle analyses}

The fatty acid composition of chicken feed (six parallel samples from each feed) and chicken breast muscle (16 randomly chosen chickens from each group) was determined by extraction, methylation and gas chromatography according to O'Fallon et al. [17]. The fatty acid methyl esters (FAME) were separated on a fused silicium dioxide capillary column $(200 \mathrm{~m} \times 0.25 \mathrm{~mm}$ id). The carrier gas was $\mathrm{H}_{2}$, and the temperature program went from $70^{\circ} \mathrm{C}$ to $230^{\circ} \mathrm{C}$. The detector temperature was $290^{\circ} \mathrm{C}$, and the run time for each sample was $90 \mathrm{~min}-$ utes. Fatty acids were identified with reference standard fatty acids (Sigma Aldrich, UK), and they were quantified by use of internal standard C13:0 (Sigma Aldrich, UK), that was added in the fatty acid extraction procedure.

\section{Statistical analyses}

The fatty acid composition and fat content of feed and chicken muscle fatty acid were calculated using Excel. Mean value \pm standard errors of the mean are presented. Independent Student's t-test was used to compare baseline values of the two groups of human participants, and paired Student's t-test to assess significance of the treatment effect in each group, for changes in serum cholesterol, triacylglycerols, HDL cholesterol, LDL cholesterol, $\mathrm{C}$-reactive protein and fatty acid composition of serum phospholipids. Control for variation in baseline value was performed using ANCOVA. Bonferroni correction was used for multiple comparisons. We used the Statistical Analysis System, SAS 9.1, and results are presented as means \pm SEM (or standard deviation when presenting the baseline characteristics). Differences were considered significant at $\mathrm{p}<0.05$.

\section{Results}

\section{Participants}

All of the 46 participants that were recruited for the study successfully completed the study. They consumed about $160 \mathrm{~g}$ chicken meat (raw weight) per day for four weeks, and they all gave a blood sample, measured blood pressure and weight at the beginning and at the end of the study.

\section{Basal characteristics}

The number of men and women, age, mean and standard deviation of height, body weight, BMI, SBP, DBP, serum cholesterol, LDL cholesterol, HDL cholesterol, triacylglycerol and C-reactive protein of the participants in the SO group and RLO group at baseline is shown in Table 2. There were no significant differences among the two groups in basal characteristics, except the number of men being lower in the SO group compared to the RLO group. Out of the 46 participants in the study, there were only 11 men. Due to the situation that some of the participants were living together in flats, and the principle of having the same type of chicken in each household to ease the cooking, there were only three men in the group eating the soybean oil supplemented chicken, and eight men in the group having the rapeseed and linseed oil fed chicken.

\section{Chicken intake}

The weight of the chickens was on average $1.09 \mathrm{~kg}$. The participants individually made a diary describing their

Table 2 Basal characteristic of the study participants in SO and RLO groups ( $n=23$ in each group)

\begin{tabular}{|c|c|c|c|c|c|}
\hline \multirow[t]{2}{*}{ Characteristics } & \multicolumn{2}{|l|}{ SO } & \multicolumn{2}{|c|}{ RLO } & \multirow[t]{2}{*}{$P^{*}$} \\
\hline & Mean & SD & Mean & SD & \\
\hline \multicolumn{6}{|l|}{$\overline{S e x}$} \\
\hline Female (n) & 20 & - & 15 & - & - \\
\hline Male (n) & 3 & - & 8 & - & - \\
\hline Age (range) years & $24(19-29)$ & - & $24(19-29)$ & - & - \\
\hline Height (m) & 1.72 & 0.08 & 1.72 & 0.09 & 0.872 \\
\hline Weight (kg) & 68.4 & 10.3 & 70.9 & 12.1 & 0.453 \\
\hline $\mathrm{BMI}\left(\mathrm{kg} / \mathrm{m}^{2}\right)$ & 23.1 & 2.7 & 23.9 & 3.7 & 0.419 \\
\hline $\mathrm{SBP}(\mathrm{mmHg})$ & 117 & 13 & 120 & 13 & 0.399 \\
\hline $\mathrm{DBP}(\mathrm{mmHg})$ & 74 & 11 & 73 & 10 & 0.503 \\
\hline Cholesterol (mmol/l) & 4.7 & 1.0 & 4.9 & 0,6 & 0.529 \\
\hline $\mathrm{LDL}(\mathrm{mmol} / \mathrm{l})$ & 3.0 & 0.8 & 3.1 & 0.7 & 0.407 \\
\hline $\mathrm{HDL}(\mathrm{mmol} / \mathrm{l})$ & 1.7 & 0.3 & 1.7 & 0.4 & 0.966 \\
\hline$\overline{\mathrm{TAG}}(\mathrm{mmol} / \mathrm{l})$ & 1.1 & 0.4 & 1.1 & 0.4 & 0.739 \\
\hline$\overline{\mathrm{CRP}}(\mathrm{mg} / \mathrm{l})$ & 2.0 & 3.0 & 2.1 & 3.3 & 0.944 \\
\hline
\end{tabular}

Body mass index (BMI), Systolic blood pressure (SBP), diastolig blood pressure (DBP), LDL cholesterol (LDL), HDL cholesterol (HDL) and C-reactive protein (CRP).

$\mathrm{SBP}=$ Systolic blood pressure.

$\mathrm{DBP}=$ Diastolic blood pressure.

*Significance in mean values between groups at baseline in one-way ANOVA. 
intake of chicken meat. In average both groups were eating 7.5 chickens during the four weeks of intervention, and they were having chicken most of the weekdays. A rough estimate made by us showed that under the given circumstances with simple kitchen facilities about $55 \%$ of the weight of raw chicken was consumed. Thus, the participants were consuming about $160 \mathrm{~g}$ chicken meat consisting in average of about $95 \mathrm{~g}$ breast muscle and $65 \mathrm{~g}$ thigh muscle per day. This corresponds to a moderate portion of chicken meat, a portion is estimated to be $175 \mathrm{~g}$ (raw meat) [18]. It has previously been shown that exchanging SO with RLO did not affect the taste and sensory aspects of the chicken meat (results not yet published).

\section{Fatty acid content in the chicken feed and meat}

The composition of the feed given to the two chicken groups is show in Table 1 , and the fatty acid composition of the feed is shown in Table 3. The feed composition was identical in the two diets with exception of the source of oils added to the diets; $4 \%$ soybean oil (SO) or $2 \%$ rapeseed oil plus $2 \%$ linseed oil (RLO). The fat content of the feed was $10.3 \%$.

The mean fatty acid content (mg fatty acid/100 g) chicken breast muscle of 16 chickens in each group is shown in Table 4 . The mean fat content was $1.5 \mathrm{~g}$ fat/ $100 \mathrm{~g}$ breast muscle in both groups. The content of the fatty acids LA, ALA, AA, EPA, DPA and DHA was significantly different in the two groups of chicken breast fillets. The content of the other fatty acids in chicken breast meat was not different between the two groups. The sum of n-3 PUFA (ALA + EPA + DPA + DHA) and the sum of LC n-3 PUFA (EPA + DPA + DHA) was much higher in the meat from the chickens fed rapeseed plus linseed oil compared to the soybean oil group.

The content of some minor and identified fatty acids; 17:0, 18:1 t6-11, 18:1c11, 20:0, 22:0, 18:3 n-6, 20:1 n-9, 20:2 n- 6 and 20:3 n-6 are not shown in the Tables 3, 4, 5 and 6 .

When calculating ratios between the fatty acids in the chicken breast muscle, both AA/EPA and n-6/n-3 were significantly lower; about 8 times and 4 times lower, respectively, in the RLO meat compared to SO (Table 4).

\section{Fatty acid composition of human serum phospholipids}

As shown in Table 5, there was no significant difference at baseline in mean percentage values of fatty acids (\% FAME) in the serum phospholipids from persons in the $\mathrm{SO}$ and RLO group. In contrast to this, after intervention, ALA and EPA, as well as 14:0 and 15:0 were significantly higher in subjects eating the RLO chicken as compared with those eating the SO fed chicken. Additionally, the RLO group tended to have higher levels of DPA $(p=0.065)$. The post-intervention AA/EPA and DPA/EPA ratio was also significantly lower in the RLO
Table 3 Fatty acid composition of chicken feed,\% fatty acid methyl ester (FAME)

\begin{tabular}{lll}
\hline & SO & RLO \\
\hline C14:0 $15: 0$ & 0.87 & 0.89 \\
\hline C16:0 & 0.17 & 0.18 \\
\hline C16:1,n-7 & 17.3 & 15.2 \\
\hline C18:0 & 1.10 & 1.16 \\
\hline C18:1,c9 & 7.79 & 8.34 \\
\hline C18:2,n-6 (LA) & 27.2 & 33.6 \\
\hline C18:3,n-3 (ALA) & 35.9 & 21.6 \\
\hline C20:4,n-6 (AA) & 3.61 & 12.33 \\
\hline C20:5,n-3 (EPA) & 0.06 & 0.09 \\
\hline C22:5,n-3 (DPA) & nd & nd \\
\hline C22:6,n-3 (DHA) & 0.04 & 0.04 \\
\hline SFA & 0.02 & 0.02 \\
\hline MUFA & 25.9 & 24.4 \\
\hline PUFA & 28.3 & 34.8 \\
\hline n-3 PUFA & 39.6 & 34.1 \\
\hline n6/n3 & 3.67 & 12.39 \\
\hline $16: 1$ n-7/16:0 & 9.82 & 1.75 \\
\hline $18: 1$ c9/18:0 & 0.06 & 0.08 \\
\hline The dits Contined 4\% soyben & 3.49 & 4.03 \\
\hline
\end{tabular}

The diets contained $4 \%$ soybean oil (SO) or $2 \%$ rapeseed oil plus $2 \%$ linseed oil (RLO). (Means from six analyses of each feed).

group. Otherwise there were no significant differences between the two groups.

Absolute values of serum phospholipid fatty acids $(-\mathrm{mg} / 100 \mathrm{ml}$ serum$)$ are shown in Table 6. The total amount of fatty acids is the same at baseline and postintervention; about $110 \mathrm{mg}$ phospholipid fatty acids/100 $\mathrm{ml}$ serum. There were no differences in fatty acid concentrations among the two groups at baseline. After intervention, the concentration of ALA, EPA and 15:0 was higher in serum from subjects eating RLO chicken as compared to subjects eating the SO chicken.

Initial and post intervention values of body weight, blood pressure and serum variables

Mean body weight, BMI, SBP, DBP, serum cholesterol, LDL cholesterol, HDL cholesterol, triacylglycerol and Creactive protein (CRP) of the participants at baseline and at the end of the intervention period (day 28) are shown in Table 7. There were no significant group differences in initial and post intervention values of body weight, BMI SBP, DBP, serum cholesterol, LDL cholesterol, HDL cholesterol, triacylglycerol and CRP, at the start of the study compared to end of the intervention period.

The body weight of participants increased in average about $0.3 \mathrm{~kg}$ during the intervention period, but this change was not statistically significant. 
Table 4 Fatty acid concentration, $\mathrm{mg} / 100 \mathrm{~g}$ of chicken breast filet from 16 animals fed a diet containing $4 \%$ soybean oil (SO) or 16 animals fed a diet containing $2 \%$ rapeseed oil plus $2 \%$ linseed oil (RLO)

\begin{tabular}{|c|c|c|c|c|c|}
\hline & \multicolumn{2}{|c|}{ SO } & \multicolumn{2}{|c|}{ RLO } & \multirow[t]{2}{*}{$P^{*}$} \\
\hline & Mean & SEM & Mean & SEM & \\
\hline C14:0 & 9.75 & 1.20 & 9.85 & 1.03 & 0.951 \\
\hline C15:0 & 2.32 & 0.25 & 2.44 & 0.22 & 0.718 \\
\hline C16:0 & 307 & 28 & 287 & 25 & 0.585 \\
\hline C16:1 n-7 & 43.9 & 6.42 & 42.2 & 4.70 & 0.832 \\
\hline C18:0 & 142 & 10.31 & 137 & 10.44 & 0.736 \\
\hline C18:1,C9 & 451 & 55.45 & 507 & 53.6 & 0.469 \\
\hline C18:2,n-6 (LA) & 379 & 42.78 & 245 & 21.0 & 0.009 \\
\hline C18:3,n-3 (ALA) & 29.9 & 4.17 & 103 & 11.54 & 0.000 \\
\hline C20:4,n-6 (AA) & 73.2 & 2.22 & 42.73 & 1.36 & 0.000 \\
\hline C20:5,n-3 (EPA) & 4.54 & 0.24 & 21.19 & 0.61 & 0.000 \\
\hline C22:5,n-3 (DPA) & 20.0 & 1.03 & 39.25 & 1.87 & 0.000 \\
\hline $\mathrm{C} 22: 6, \mathrm{n}-3$ (DHA) & 14.1 & 0.97 & 20.41 & 1.10 & 0.000 \\
\hline SFA & 459 & 39.74 & 433 & 36.0 & 0.634 \\
\hline MUFA & 495 & 61.68 & 550 & 58.2 & 0.523 \\
\hline PUFA & 521 & 48.04 & 472 & 34.8 & 0.420 \\
\hline n-3 PUFA & 68.5 & 4.73 & 184 & 13.3 & 0.000 \\
\hline LC n-3 PUFA & 38.6 & 1.72 & 80.9 & 2.97 & 0.000 \\
\hline AA/EPA & 16.55 & 0.71 & 2.03 & 0.07 & 0.000 \\
\hline$n-6 / n-3$ & 6.48 & 0.26 & 1.56 & 0.02 & 0.000 \\
\hline $16: 1 n-7 / 16: 0$ & 0.13 & 0.01 & 0.14 & 0.00 & 0.240 \\
\hline 18:1c9/18:0 & 3.03 & 0.18 & 3.65 & 0.13 & 0.010 \\
\hline AA/LA & 0.23 & 0.03 & 0.19 & 0.01 & 0.146 \\
\hline EPA/ALA & 0.22 & 0.05 & 0.23 & 0.02 & 0.879 \\
\hline DPA/EPA & 4.52 & 0.28 & 1.86 & 0.09 & 0.000 \\
\hline DHA/DPA & 0.72 & 0.05 & 0.53 & 0.02 & 0.001 \\
\hline
\end{tabular}

(Mean values and standard errors, SEM).

*Significance in mean values between groups.

SFA: sum of $14: 0,16: 0$ and 18:0.

MUFA: sum of $16: 1 \mathrm{n}-7$ and 18:1 n-9.

PUFA: sum of LA, ALA, AA, EPA, DPA and DHA

n-3 PUFA: sum of ALA, EPA, DPA and DHA.

LC $n-3$ PUFA: sum of EPA, DPA and DHA.

$n-6 / n-3:(L A+A A) /(A L A+E P A+D P A+D H A)$

Serum cholesterol varied from $3.0 \mathrm{mmol} / \mathrm{l}$ (in one of the males), to $7.6 \mathrm{mmol} / \mathrm{l}$ (in one of the females). The CRP was below $10 \mathrm{mg} / \mathrm{l}$ in all except three readings, and two of the values were just above 10. One participant had CRP of $173 \mathrm{mg} / \mathrm{l}$. This reading was removed from the data. All the other analyzed values of these persons were not extremes, and we chose not to remove any other values. The participants with values outside the given reference for their age group were informed about the findings and advised to see their personal physician for a check.

\section{Discussion}

The present study shows that a daily intake of a moderate portion of chicken meat for 4 weeks can appreciably increase the concentration of EPA in serum phospholipids of young healthy humans, provided that the chickens had been fed rapeseed and linseed oil instead of similar amounts of soybean oil.

The daily intake of chicken meat, about $160 \mathrm{~g} /$ day, is much higher than the average daily intake of chicken meat in the Norwegian population; being about $50 \mathrm{~g} /$ day $[2,3]$. The total average intake of meat per person in Norway is estimated in two different reports to be about $130 \mathrm{~g} /$ day [2], and $200 \mathrm{~g} /$ day [3]. The subjects were advised to follow their normal diet, but to eat as much as possible of the two chickens they received each week, in preference to other meats. Their average total meat intake may therefore have been somewhat higher than $160 \mathrm{~g} /$ day during the study. In the present study the participants were mostly students at The Norwegian University of Life Sciences, living in student accommodation houses and having a limited budget. Since meat is expensive compared to cereal based food, they are likely to have less meat in their regular diet than the average Norwegian intake. Some of the students at The Norwegian University of Life Sciences are taking a course in nutrition where they undergo a dietary assessment showing that they have a diet based on much bread and cereals, milk and milk products, some meat, some fish, margarine, vegetables and fruit.

\section{The chickens}

The RLO feed resulted in a significant increase in EPA, DPA and DHA and a decrease in AA in the chicken breast fillets (Table 4). The chicken is thus a good producer of LC n-3 PUFA from ALA, and chicken meat has potential to be a good source of LC n-3 PUFA in the human diet. The concentration of LC PUFA (AA + EPA + DPA + DHA) made from LA and ALA was $112 \mathrm{mg} / 100 \mathrm{~g}$ in the SO chicken breast muscle and $124 \mathrm{mg} / 100 \mathrm{~g}$ in the RLO group. The percentages of LA + ALA in the two feeds were $40 \%$ and $34 \%$ of the total fatty acids, respectively, indicating that the synthesis of LC PUFA from LA and ALA was higher in breast muscle from the RLO group compared to the SO group. Thus a diet containing rapeseed and linseed oil appears to trigger the chicken to synthesize LC PUFA. This has also been indicated by others in chickens [4], pigs [19] and bulls [20].

The ability of the chickens and other domestic animals to produce EPA, DPA and DHA from ALA should be valued and given more focus seen in light of the limitations in the world supply of LC n-3 PUFAs from fish and marine sources. To replace the soybean oil (that is now the commonly used feed oil) with linseed and rapeseed oil seems to be an efficient way to increase the intake of LC n-3 PUFA for humans without having to change dietary habits or to take fish oil supplement pills. 
Table 5 Fatty acid composition of serum phospholipids at baseline and post-intervention in persons eating chickens fed soybean oil supplement (SO) and rapeseed and linseed oil supplement (RLO), (\% of total fatty acids, FAME)

\begin{tabular}{|c|c|c|c|c|c|c|c|c|c|c|}
\hline \multirow[t]{3}{*}{ Fatty acid } & \multicolumn{4}{|c|}{ SO group $(n=23)$} & \multicolumn{4}{|c|}{ RLO group $(n=23)$} & \multirow[t]{3}{*}{$P \S$} & \multirow[t]{3}{*}{$P \boldsymbol{P q}$} \\
\hline & \multicolumn{2}{|c|}{ Baseline } & \multicolumn{2}{|c|}{ Post-intervention } & \multicolumn{2}{|c|}{ Baseline } & \multicolumn{2}{|c|}{ Post-intervention } & & \\
\hline & Mean & $\overline{\text { SEM }}$ & Mean & SEM & Mean & $\overline{\text { SEM }}$ & Mean & SEM & & \\
\hline $\mathrm{C} 14: 0$ & 0.37 & 0.02 & 0.34 & 0.02 & 0.37 & 0.02 & 0.41 & 0.03 & 0.894 & 0.029 \\
\hline $\mathrm{C} 15: 0$ & 0.23 & 0.01 & 0.21 & 0.01 & 0.25 & 0.01 & 0.25 & 0.01 & 0.127 & 0.004 \\
\hline $\mathrm{C} 16: 0$ & 29.5 & 0.45 & 29.2 & 0.41 & 29.4 & 0.39 & 28.8 & 0.41 & 0.903 & 0.460 \\
\hline $\mathrm{C} 16: 1, \mathrm{n}-7$ & 0.67 & 0.05 & 0.61 & 0.04 & 0.57 & 0.04 & 0.57 & 0.03 & 0.114 & 0.455 \\
\hline $\mathrm{C} 18: 0$ & 13.5 & 0.35 & 13.2 & 0.31 & 13.4 & 0.28 & 13.1 & 0.29 & 0.966 & 0.873 \\
\hline $\mathrm{C} 18: 1, \mathrm{C9}$ & 10.18 & 0.31 & 9.42 & 0.31 & 9.32 & 0.26 & 9.48 & 0.27 & 0.042 & 0.887 \\
\hline C18:2,n-6 (LA) & 20.2 & 0.58 & 20.3 & 0.47 & 21.0 & 0.53 & 20.7 & 0.52 & 0.285 & 0.537 \\
\hline C18:3,n-3 (ALA) & 0.27 & 0.02 & 0.23 & 0.01 & 0.26 & 0.02 & 0.36 & 0.03 & 0.735 & 0.000 \\
\hline C20:4,n-6 (AA) & 8.41 & 0.39 & 10.21 & 0.46 & 9.16 & 0.36 & 9.66 & 0.34 & 0.167 & 0.340 \\
\hline C20:5,n-3 (EPA) & 1.03 & 0.09 & 0.80 & 0.05 & 1.09 & 0.09 & 1.26 & 0.09 & 0.669 & 0.000 \\
\hline $\mathrm{C} 22: 5, \mathrm{n}-3$ (DPA) & 0.91 & 0.05 & 0.92 & 0.05 & 0.92 & 0.05 & 1.08 & 0.06 & 0.836 & 0.065 \\
\hline $\mathrm{C} 22: 6, n-3(\mathrm{DHA})$ & 4.94 & 0.28 & 4.77 & 0.26 & 4.63 & 0.26 & 4.57 & 0.20 & 0.421 & 0.545 \\
\hline SFA & 43.3 & 0.19 & 42.7 & 0.22 & 43.3 & 0.17 & 42.3 & 0.21 & 0.736 & 0.163 \\
\hline$\overline{M U F A}$ & 10.8 & 0.32 & 10.0 & 0.32 & 9.89 & 0.29 & 10.0 & 0.29 & 0.034 & 0.967 \\
\hline PUFA & 35.7 & 0.42 & 37.2 & 0.51 & 37.1 & 0.53 & 37.6 & 0.46 & 0.052 & 0.540 \\
\hline n-3 PUFA & 7.15 & 0.35 & 6.72 & 0.29 & 6.90 & 0.34 & 7.26 & 0.27 & 0.614 & 0.187 \\
\hline LCn-3 PUFA & 6.88 & 0.36 & 6.49 & 0.30 & 6.64 & 0.35 & 6.90 & 0.27 & 0.633 & 0.307 \\
\hline AA/EPA & 9.25 & 0.74 & 13.84 & 1.07 & 9.73 & 0.89 & 8.72 & 0.88 & 0.679 & 0.001 \\
\hline$n-6 / n-3$ & 4.23 & 0.23 & 4.73 & 0.22 & 4.62 & 0.25 & 4.33 & 0.19 & 0.251 & 0.166 \\
\hline $16: 1 n-7 / 16: 0$ & 0.02 & 0.00 & 0.02 & 0.00 & 0.02 & 0.00 & 0.02 & 0.00 & 0.100 & 0.542 \\
\hline 18:1 c9/18:0 & 0.76 & 0.03 & 0.72 & 0.03 & 0.70 & 0.03 & 0.73 & 0.03 & 0.113 & 0.849 \\
\hline EPA/ALA & 4.19 & 0.46 & 3.66 & 0.27 & 4.75 & 0.67 & 3.85 & 0.35 & 0.498 & 0.672 \\
\hline DPA/EPA & 0.95 & 0.05 & 1.22 & 0.08 & 0.91 & 0.05 & 0.88 & 0.03 & 0.607 & 0.000 \\
\hline DHA/DPA & 5.73 & 0.38 & 5.49 & 0.36 & 5.30 & 0.37 & 4.56 & 0.33 & 0.429 & 0.065 \\
\hline
\end{tabular}

§Significance in mean values between groups at baseline.

- Significance in mean values between groups after the 4 week intervention period.

SFA: sum of 14:0, 16:0 and 18:0.

MUFA: sum of $16: 1 \mathrm{n}-7$ and $18: 1 \mathrm{n}-9$.

PUFA: sum of LA, ALA, AA, EPA, DPA and DHA

n-3 PUFA: sum of ALA, EPA, DPA and DHA.

LC $n-3$ PUFA: sum of EPA, DPA and DHA.

$n-6 / n-3:(L A+A A) /(A L A+E P A+D P A+D H A)$.

As seen from Table 4, the daily intake of EPA + DPA + DHA when eating a portion of $175 \mathrm{~g}$ of breast muscle from the RLO chicken would be $142 \mathrm{mg}$. This is $57 \%$ of the proposed EFSA reference intake value of LC n-3 PUFA (250 mg/day) to reduce the risk of CVD [21]. Chicken breast meat from the SO fed group contained $68 \mathrm{mg}$ in $175 \mathrm{~g}$ breast meat, thus a portion of the RLO chicken breast meat contained $74 \mathrm{mg}$ more LC n-3 PUFA than the traditional SO chicken. The optimal dose for LC n-3 PUFA remains to be established. The EFSA Panel in 2010 [22] has suggested that $450 \mathrm{mg}$ may be a recommended daily intake of LC n-3 PUFA. This shows that even if all meat consumed had about the same fatty acid composition as the RLO breast meat from this experiment, it would not be enough alone to cover the recommended intake of LC n-3 PUFA.

The chicken thigh meat may be about four to five times higher in fat content compared to the breast meat [4,23], but the percentage of LC n-3 PUFA ( $\mathrm{g} / 100 \mathrm{~g}$ fatty acids) is lower in thigh meat compared to breast meat [4]. Thus, the LC n-3 PUFA content is somewhat (about 30-50\%) higher in thigh muscle compared to breast muscle [4], and by consuming $175 \mathrm{~g}$ of the RLO thigh muscle the LC n-3 PUFA intake can be estimated to be about $190 \mathrm{mg}$ instead of $142 \mathrm{mg}$ when consuming the breast muscle.

The concentration of AA was lower in the RLO chicken breast muscle compared to SO. This is in accordance to 
Table 6 Fatty acid concentration ( $\mathrm{mg} / 100 \mathrm{ml}$ serum) of serum phospholipids at baseline and post-intervention in persons eating chickens fed soybean oil supplement (SO) and rapeseed and linseed oil supplement (RLO)

\begin{tabular}{|c|c|c|c|c|c|c|c|c|c|c|}
\hline & \multicolumn{4}{|c|}{ SO group $(n=23)$} & \multicolumn{4}{|c|}{ RLO group $(n=23)$} & \multirow[t]{3}{*}{$P \S$} & \multirow[t]{3}{*}{$P \Phi$} \\
\hline & \multicolumn{2}{|c|}{ Baseline } & \multicolumn{2}{|c|}{ Post-intervention } & \multicolumn{2}{|c|}{ Baseline } & \multicolumn{2}{|c|}{ Post-intervention } & & \\
\hline & Mean & $\overline{\text { SEM }}$ & Mean & $\overline{\text { SEM }}$ & Mean & $\overline{\text { SEM }}$ & Mean & SEM & & \\
\hline C14:0 & 0.42 & 0.03 & 0.39 & 0.03 & 0.43 & 0.04 & 0.46 & 0.03 & 0.889 & 0.158 \\
\hline C15:0 & 0.26 & 0.01 & 0.24 & 0.01 & 0.28 & 0.01 & 0.28 & 0.01 & 0.192 & 0.033 \\
\hline $\mathrm{C} 16: 0$ & 33.99 & 1.47 & 33.49 & 1.60 & 33.73 & 1.23 & 31.87 & 1.20 & 0.889 & 0.423 \\
\hline $\mathrm{C} 16: 1, \mathrm{n}-7$ & 0.79 & 0.08 & 0.72 & 0.07 & 0.67 & 0.06 & 0.65 & 0.06 & 0.224 & 0.449 \\
\hline $\mathrm{C18:0}$ & 15.34 & 0.58 & 15.00 & 0.62 & 15.30 & 0.50 & 14.53 & 0.56 & 0.958 & 0.576 \\
\hline $\mathrm{C} 18: 1, \mathrm{C9}$ & 11.64 & 0.50 & 10.82 & 0.63 & 10.75 & 0.55 & 10.56 & 0.54 & 0.238 & 0.757 \\
\hline C18:2,n-6 (LA) & 22.90 & 0.76 & 23.00 & 0.86 & 23.96 & 0.88 & 22.89 & 0.91 & 0.368 & 0.932 \\
\hline C18:3,n-3 (ALA) & 0.31 & 0.03 & 0.27 & 0.02 & 0.31 & 0.03 & 0.40 & 0.03 & 0.912 & 0.001 \\
\hline C20:4,n-6 (AA) & 9.72 & 0.61 & 11.59 & 0.65 & 10.40 & 0.48 & 10.63 & 0.45 & 0.386 & 0.234 \\
\hline C20:5,n-3 (EPA) & 1.20 & 0.13 & 0.92 & 0.08 & 1.23 & 0.10 & 1.40 & 0.10 & 0.860 & 0.001 \\
\hline $\mathrm{C} 22: 5, \mathrm{n}-3$ (DPA) & 1.04 & 0.07 & 1.04 & 0.06 & 1.04 & 0.06 & 1.18 & 0.07 & 0.944 & 0.128 \\
\hline $\mathrm{C} 22: 6, n-3(\mathrm{DHA})$ & 5.74 & 0.44 & 5.44 & 0.38 & 5.26 & 0.31 & 5.04 & 0.26 & 0.382 & 0.395 \\
\hline
\end{tabular}

§Significance in mean values between groups at baseline.

- Significance in mean values between groups after the 4 week intervention period.

findings by Poureslami et al. and is shown in both breast muscle and in thigh muscle [4]. The reduction in AA concentration in meat may have implications for the consumer given the nature of the competition between AA and EPA for binding to enzymes and cellular structures [7]. It has been found that purified COX-1 oxygenates EPA at a rate which is only $10 \%$ of the rate for AA, while EPA significantly inhibits AA oxygenation by COX-1 [24]. A portion of breast meat from the RLO chicken contained $75 \mathrm{mg} \mathrm{AA}$, while the SO meat contained $128 \mathrm{mg}$, and the ratio of AA/EPA was only 2 in the RLO chicken breast meat compared to nearly 17 in the meat in the SO group. Such a big difference in AA and EPA balance could be expected to have an impact on the prostanoid synthesis both for the chicken itself and for the consumer eating the chicken.

\section{The human intervention study}

In the present study, an increase in EPA and ALA concentrations, and a decrease in the ratio AA/EPA in serum phospholipids were shown in the persons consuming the RLO chickens. This is in line with the study of Weill et al. and McAfee et al. showing that subjects consuming meat from animals offered a concentrate feed supplemented with linseed oil or a grass based diet had higher LC n-3 PUFA concentrations in erythrocytes, platelets and plasma compared to subjects consuming animal products from animals fed a standard diet $[25,26]$.

Table 7 Weight, BMI, systolic blood pressure (SBP), diastolic blood pressure (DBP), total cholesterol, LDL cholesterol (LDL), HDL cholesterol (HDL), triacylglycerol (TAG) and C-Reactive Protein (CRP) of study participants at baseline and post-intervention in SO and RLO treatment groups ( $n=23$ participants in each group)

\begin{tabular}{|c|c|c|c|c|c|c|c|c|c|c|}
\hline & \multicolumn{4}{|c|}{ SO group $(n=23)$} & \multicolumn{4}{|c|}{ RLO group $(n=23$ ) } & \multirow[t]{3}{*}{$P \S$} & \multirow[t]{3}{*}{$P \Phi$} \\
\hline & \multicolumn{2}{|c|}{ Baseline } & \multicolumn{2}{|c|}{ Post-intervention } & \multicolumn{2}{|c|}{ Baseline } & \multicolumn{2}{|c|}{ Post-intervention } & & \\
\hline & Mean & SEM & Mean & SEM & Mean & SEM & Mean & SEM & & \\
\hline Weight (kg) & 68.39 & 2.15 & 68.57 & 2.15 & 70.90 & 2.53 & 71.31 & 2.52 & 0.453 & 0.414 \\
\hline $\mathrm{BMI}\left(\mathrm{kg} / \mathrm{m}^{2}\right)$ & 23.11 & 0.57 & 23.17 & 0.57 & 23.89 & 0.77 & 24.02 & 0.77 & 0.419 & 0.376 \\
\hline $\mathrm{SBP}(\mathrm{mmHg})$ & 116.7 & 2.30 & 115.5 & 1.93 & 119.9 & 2.42 & 117.9 & 2.15 & 0.399 & 0.366 \\
\hline $\mathrm{DBP}(\mathrm{mmHg})$ & 73.63 & 1.60 & 70.7 & 1.40 & 73.2 & 1.84 & 71.3 & 1.84 & 0.503 & 0.903 \\
\hline Cholesterol (mmol/l) & 4.72 & 0.20 & 4.59 & 0.18 & 4.87 & 0.13 & 4.68 & 0.13 & 0.529 & 0.681 \\
\hline $\mathrm{LDL}(\mathrm{mmol} / \mathrm{l})$ & 2.95 & 0.17 & 2.88 & 0.16 & 3.13 & 0.15 & 3.05 & 0.12 & 0.407 & 0.408 \\
\hline $\mathrm{HDL}(\mathrm{mmol} / \mathrm{l})$ & 1.65 & 0.06 & 1.61 & 0.07 & 1.66 & 0.08 & 1.60 & 0.08 & 0.966 & 0.902 \\
\hline TAG $(\mathrm{mmol} / \mathrm{l})$ & 1.10 & 0.08 & 1.10 & 0.13 & 1.06 & 0.09 & 1.06 & 0.10 & 0.739 & 0.810 \\
\hline $\mathrm{CRP}(\mathrm{mg} / \mathrm{l})$ & 1.99 & 0.62 & 2.53 & 0.68 & 2.06 & 0.69 & 2.38 & 0.64 & 0.944 & 0.872 \\
\hline
\end{tabular}

§Significance in mean values between groups at baseline.

$\uparrow$ Significance in mean values between groups after the 4 week intervention period. 
The fatty acid composition of serum phospholipids has become established as a valid marker for assessing the status of various fatty acids and to predict dietary fat intakes [27]. As reviewed by Fekete et al. [28], four weeks intervention time and sampling of serum phospholipid fatty acids was a suitable method for studying long-term LC n-3 status in humans.

The content of EPA in $160 \mathrm{~g}$ breast muscle from the RLO chicken was $34 \mathrm{mg}$. In contrast, the content of EPA in the SO chicken breast muscle was only $7 \mathrm{mg}$ per day. Since the participants were not eating oily fish during the study, most of their dietary EPA intake originated from the chicken meat. EPA is synthesized in the body from ALA, but there are variations in the ability to convert ALA to EPA [29-31], and it may be speculated that to some persons a dietary intake of EPA is imperative. The concentration of EPA in serum phospholipids was $1.4 \mathrm{mg} / 100 \mathrm{ml}$ serum (about $1.3 \%$ of FAME) in the RLO treatment group and $0.9 \mathrm{mg} / 100 \mathrm{ml}$ (about $0.8 \%$ of FAME) in the SO group. The EPA concentrations varied between the persons, and at post intervention time three persons in the SO diet group had levels lower than 0.5 mg EPA in phospholipids/100 ml serum (0.5\% FAME), but in the RLO group no persons had lower levels than $0.5 \mathrm{mg}$ EPA in phospholipids $/ 100 \mathrm{ml}$ serum post trial.

The sum of EPA plus DHA in serum phospholipids have in populations studies been linked to assess risk of heart disease [32,33]. EPA + DHA levels amounting to more than $4.6 \%$ of total fatty acids in serum phospholipids have been associated with a $70 \%$ lower risk compared to those with a lower level of these fatty acids $[32,33]$. In the present study, at baseline, three test subjects in the SO group had less than $4.6 \%$ of EPA + DHA (percent of total fatty acids) in serum phospholipids, and five subjects in the RLO were below 4.6\%. After the intervention period, two of the three persons in the SO group had reduced their EPA + DHA sum, while all five of the persons in the RLO group improved (increased) their sum of percent EPA + DHA in serum phospholipids. Thus, in the present study, nearly $1 / 5$ of the subjects had less than $4.6 \%$ of EPA + DHA in their serum phospholipids. Consumption of the RLO chicken gave an increase in EPA + DHA in serum phospholipids of persons already low in EPA + DHA, and this might theoretically contribute to reduce the risk of coronary heart disease [32,33].

The DPA concentration in serum phospholipids was at about the same level as EPA, but the DHA concentration in serum phospholipids was about five times higher in both treatment groups. In the chicken meat however, it is different; DPA was the most abundant of these three fatty acids, and especially in the RLO chicken there was much DPA (39 mg/100 g meat, Table 4). DPA can be converted to both EPA and DHA [34]. The DPA percentage in serum phospholipids of the subjects eating the RLO chicken showed a tendency to be higher compared to those eating the SO chicken, and to have a significantly lower DPA/ EPA ratio (Table 5). No increase in the serum phospholipid concentration of DHA in the test subjects eating RLO chicken meat was observed, although EPA was enhanced. The reasons for this are unknown. One possible explanation might be faster removal of DHA than of EPA from the blood plasma of our test subjects.

The concentration of ALA in serum phospholipids was about $30 \%$ higher in the RLO group than the SO group. This is plausible since the amount of ALA in the RLO breast muscle was higher (three times higher) than the $\mathrm{SO}$ breast meat.

The ratio AA/EPA was significantly lower in serum phospholipids from the persons eating the RLO chicken. This ratio has been shown to affect the production of different types of eicosanoids and prostanoids [35], and the production of eicosanoids and prostanoids may be altered in a favorable direction towards lower production of thromboxanes of the 2-series which should imply reduced risk of thrombosis.

There were no differences in the concentration of AA in serum phospholipids between the subjects consuming RLO and SO chickens. In the SO group, the AA concentration was higher at post-intervention compared to baseline being $10.2 \%$ and $8.4 \%$, (Table 5 ). It may be speculated that high intake of AA rich meat during the intervention period may increase AA levels in serum phospholipids. However, Kawabata et al. showed no correlations between dietary AA intake and AA in blood lipid fractions [36].

The difference in numbers of men and women in the two intervention groups was of concern, since women have been reported to have a more efficient synthesis of EPA, DPA and DHA from ALA [37]. When calculating the results for men and women separately, there was, however, no difference between the sexes in this study, and the final results would not be different if we excluded the men from the study.

There were no significant differences in serum pre or post trial concentrations of total cholesterol, LDL cholesterol, HDL cholesterol or triacylglycerol in the two intervention groups. This is in accordance to the study of McAfee et al. [26], where the participants were consuming red meat with different amounts of LC PUFAs. Even if the intake of LC n-3 PUFA is nearly twice as high in the RLO group compared to the SO group, the intakes may be too low to significantly affect serum cholesterol or triacylglycerol [38,39].

In the present study with young subjects having normal blood pressure there were no effects on blood pressure when eating the two different meats. Long chain n-3 PUFAs have been shown to have mild antihypertensive 
effect $[11,40]$, however, the difference in LC n-3 PUFA intake between the two groups may have been too low to reveal any effects. There were no differences in CRP between the two groups. Although research studies have suggested that LC n-3 PUFA may have antiinflammatory effects $[12,39]$, this was not observed in the present study with young healthy persons.

\section{Conclusion}

Ingestion of chicken meat from chickens fed a diet containing rapeseed plus linseed oil increased EPA and reduced the AA/EPA ratio in serum phospholipids in young healthy persons compared to persons eating chicken meat from birds raised on a diet containing soybean oil (similar to a commercially available chicken). All the five persons who had less than $4.6 \%$ of EPA + DHA in their serum phospholipids at baseline, improved (increased) the sum of EPA + DHA after the four week intervention when consuming chickens fed rapeseed plus linseed oil supplementation.

The chicken produces some LC n-3 PUFA from ALA, and chicken meat may become a good dietary source of LC n-3 PUFA provided that the birds are given rapeseed and linseed oil instead of soybean oil. This can be an efficient and easy way to increase the amount of LC n-3 PUFA in the general human diet, without having to make any changes in food habits.

\section{Abbreviations}

AA: Arachidonic acid 20:4n-6; ALA: Alpha-linolenic acid 18:3n-3; BMl: Body mass index; CRP: C-reactive protein; DBP: Diastolic Blood Pressure; DHA: Docosahexaenoic acid 22:6n-3; DPA: Docosapentaenoic acid 22:5n-3; EPA: Eicosapentaenoic acid 20:5n-3; HDL: High density lipoprotein cholesterol; LA: Linoleic acid; LC PUFA: Long chain polyunsaturated fatty acids; LDL: Low density lipoprotein cholesterol; PUFA: Polyunsaturated fatty acids; RLO: Rapeseed plus linseed oil; SBP: Systolic Blood Pressure; SO: Soybean oil; TC: Total cholesterol.
\end{abstract}

\section{Competing interests}

The authors declare no conflict of interest. All authors of this research have no conflict of interest related with employment, consultancies, stock ownership, grants or other funding.

\section{Authors' contributions}

Each author has participated sufficiently, intellectually or practically, in the work to take public responsibility for the content of the article, including the conception, design, and conduction of the experiment and for data interpretation (authorship). NFN, TJM, MA and AH carried out the study, data analyses, performed the statistical analysis and helped to draft the manuscript. ATH participated in the design, data analyses and writing of the study. All authors read and approved the final manuscript.

\section{Acknowledgement}

The present study was funded by grant no 190399 from the Norwegian Research Council, and Animalia; the Norwegian Meat and Poultry Research Centre. The centre provided funding, but had no influence on the design, choice of methodology or interpretation of the results.

Many people have contributed in different stages of the project. We want especially to thank the personnel at the Norwegian University of Life Sciences, and at the Animal Production Experimental Center, Ås, Norway, with a special thank to Frank Sundby, Marianne Skarra, Inger J. Jørgensen, Eva Kristensen and Ellen M. Kvarme for helping to carry out the study. Also expressed gratitude to Tore Bolstad for performing the fatty acid analyzes, to
Olav A. Christophersen and Graham Lyons for valuable discussions of the manuscript. And a big thank to the volunteers who gave us of their time.

\section{Author details}

${ }^{1}$ Department of Animal and Aquacultural Sciences, The Norwegian University of Life Sciences, P.O.BOX 5003, Ås 1432, Norway. ${ }^{2}$ Section of Preventive Medicine and Epidemiology, University of Oslo, Blindern, P.O.BOX 113, Oslo 0318, Norway.

Received: 15 June 2012 Accepted: 12 August 2012

Published: 22 August 2012

\section{References}

1. Pan A, Sun Q, Bernstein AM, et al: Red Meat Consumption and Mortality. Results from 2 Prospective Cohort Studies. Arch Intern Med Published online March 12, 2012. 172:555-563.

2. Kjøttets tilstand: Norway: Animalia; 2011. http://www.animalia.no/upload/ Kj\%c3\%b8ttets_tilstand_2011/Kjottets_tilstand_2011.pdf Assessed March 2012.

3. Utviklingen i norsk kosthold: Norway: Helsedirektoratet; 2011. http://www. helsedirektoratet.no/publikasjoner/utviklingen-i-norsk-kosthold-2011kortversjon/Publikasjoner/utviklingen-norsk-kosthold-2011-kort.pdf. Assessed March 2012.

4. Poureslami R, Raes $K$, Huyghebaert $G$, et al: Effects of diet, age and gender on the polyunsaturated fatty acid composition of broiler anatomical compartments. Br Poult Sci 2010, 51:81-91.

5. Haug A, Eich-Greatorex S, Bernhoft A, et al: Effect of dietary selenium and omega-3 fatty acids on muscle composition and quality in broilers. Lipids Health Dis 2007, 6:29.

6. Simopoulos AP: Human requirement for $\mathrm{N}-3$ polyunsaturated fatty acids. Poult Sci 2000, 79:961-970.

7. Christophersen OA, Haug A: Animal products, diseases and drugs: a plea for better integration between agricultural sciences, human nutrition and human pharmacology. Lipids Health Dis 2011, 10:16.

8. Griffin BA: How relevant is the ratio of dietary $n-6$ to $n-3$ polyunsaturated fatty acids to cardiovascular disease risk? Evidence from the OPTILIP study. Curr Opin Lipidol 2008, 1:57-62.

9. Okuyama H: High $n-6$ to $n-3$ ratio of dietary fatty acids rather than serum cholesterol as a major risk factor for coronary heart disease. Eur J Lipid Sci Technol 2001, 103:418-422.

10. Lands WEM: Biochemistry and physiology of $n-3$ fatty acids. FASEB J 1992, 6:2530-2536.

11. Appel $L F$, Miller $E R$, Sidler AJ, et al: Does supplementation of diet with 'fish oil' reduce blood pressure? A meta-analysis of controlled clinical trials. Arch Intern Med 1993, 153:1429-1438.

12. Wall R, Ross RP, Fitzgerald GF, et al: Fatty acids from fish: the antiinflammatory potential of long-chain omega-3 fatty acids. Nutr Rev 2010, 68:280-289.

13. USDA: Food composition data. 2012. http://ndb.nal.usda.gov/ndb/foods/ show 2558 ?fg $=\& \mathrm{man}=\& \mid$ facet $=\&$ count $=\& \mathrm{max}=25 \&$ sort $=\&$ qlookup=pork + raw +meat\&offset=\&format=Full\&new=. Assessed March 2012.

14. Icelandic food composition table. 2012. http://www.matis.is/SGEM/en/search/. Assessed March 2012.

15. Gibbs RA, Rymer C, Givens DI: Postgraduate Symposium: Long-chain n-3 PUFA: intakes in the UK and the potential of a chicken meat prototype to increase them. Proc Nutr Soc 2010, 69:144-155.

16. Haug A, Olesen I, Christophersen OA: Individual variation and intraclass correlation in arachidonic acid and eicosapentaenoic acid in chicken muscle. Lipids Health Dis 2010, 9:37.

17. O'Fallon JV, Busboom JR, Nelson ML, et al: A direct method for fatty acid methyl ester synthesis: application to wet meat tissues, oils, and feedstuffs. J Anim Sci 2007, 85:1511-1521.

18. Mat på Data: Norway: Matportalen; 2012. http://matportalen.no/verktoy/ mat_pa_data/. Assessed March 2012.

19. Juárez $\mathrm{M}$, Dugan $M E$, Aldai N, et al: Feeding co-extruded flaxseed to pigs: effects of duration and feeding level on growth performance and backfat fatty acid composition of grower-finisher pigs. Meat Sci 2010, 84:578-584.

20. Herdmann A, Martin J, Nuernberg G, et al: Effect of dietary $n-3$ and $n-6$ PUFA on lipid composition of different tissues of German Holstein bulls 
and the fate of bioactive fatty acids during processing. J Agric Food Chem 2010, 58:8314-8321.

21. EFSA: Scientific opinion. Labelling reference intake values for $n-3$ and $n-6$ polyunsaturated fatty acids. The EFSA Journal 2009, 1176:1-11.

22. EFSA panel on Dietetic Products: Nutrition and Allergies (NDA). 8th edition: The EFSA Journal; 2010:1461. http://www.efsa.europa.eu/it/efsajournal/doc/ 1461.pdf. Assessed March 2012.

23. Fineli database: 2012. http://www.fineli.fi/foodsearch.php? name $=$ chicken\&stype=s\&lang=en Assessed August 2012.

24. Wada M, DeLong CJ, Hong YH, et al: Enzymes and receptors of prostaglandin pathways with arachidonic acid-derived versus eicosapentaenoic acid-derived substrates and products. J Biol Chem 2007, 282:22254-22266.

25. Weill P, Schmitt B, Chesneau G, Daniel N, Safraou F, Legrand P: Effects of introducing linseed in livestock diet on blood fatty acid composition of consumers of animal products. Ann Nutr Metab 2002, 46:182-191.

26. McAfee AJ, McSorley EM, Cuskelly GJ, et al: Red meat from animals offered a grass diet increases plasma and platelet n-3 PUFA in healthy consumers. Br J Nutr 2011, 105:80-89.

27. Hjartåker A, Lund E, Bjerve KS: Serum phospholipid fatty acid composition and habitual intake of marine foods registered by a semi-quantitative food frequency questionnaire. Eur J Clin Nutr 1997, 51:736-742.

28. Fekete K, Marosvölgyi T, Jakobik V, et al: Methods of assessment of $n-3$ long-chain polyunsaturated fatty acid status in humans: a systematic review. Am J Clin Nutr 2009, 89:2070S-2084S.

29. Simopoulos AP: Genetic variants in the metabolism of omega- 6 and omega- 3 fatty acids: their role in the determination of nutritional requirements and chronic disease risk. Exp Biol Med (Maywood) 2010, 235:785-795.

30. Lemaitre RN, Tanaka T, Tang W, et al: Genetic loci associated with plasma phospholipid $\mathrm{n}-3$ fatty acids: a meta-analysis of genome-wide association studies from the CHARGE Consortium. PLoS Genet 2011, 7:e1002193.

31. Brenna JT: Efficiency of conversion of alpha-linolenic acid to long chain n-3 fatty acids in man. Curr Opin Clin Nutr Metab Care 2002, 5:127-132.

32. Holub DJ, Holub BJ: Omega-3 fatty acids from fish oils and cardiovascular disease. Mol Cell Biochem 2004, 263:217-225.

33. Lemaitre RN, King IB, Mozaffarian D, Kuller LH, Tracy RP, Siscovick DS: $n-3$ Polyunsaturated fatty acids, fatal ischemic heart disease, and nonfatal myocardial infarction in older adults: The Cardiovascular Heart Study. Am J Clin Nutr 2003, 77:319-325.

34. Kaur G, Begg DP, Barr D, et al: Short-term docosapentaenoic acid (22:5 n-3) supplementation increases tissue docosapentaenoic acid, DHA and EPA concentrations in rats. Br J Nutr 2010, 103:32-37.

35. Sabater J, Masclans JR, Sacanell J, et al: Effects of an omega-3 fatty acidenriched lipid emulsion on eicosanoid synthesis in acute respiratory distress syndrome (ARDS): A prospective, randomized, double-blind, parallel group study. Nutr Metab (Lond) 2011, 8:22

36. Kawabata T, Hirota S, Hirayama T, et al: Associations between dietary n-6 and $n-3$ fatty acids and arachidonic acid compositions in plasma and erythrocytes in young and elderly Japanese volunteers. Lipids Health Dis 2011, 10:138.

37. Burdge GC, Calder PC: Conversion of alpha-linolenic acid to longer-chain polyunsaturated fatty acids in human adults. Reprod Nutr Dev 2005, 45:581-597.

38. Balk EM, Lichtenstein AH, Chung M, et al: Effects of omega-3 fatty acids on serum markers of cardiovascular disease risk: a systematic review. Atherosclerosis 2006, 189:19-30.

39. Kromhout D, Yasuda S, Geleijnse JM, et al: Fish oil and omega-3 fatty acids in cardiovascular disease: do they really work? Eur Heart J 2012, 33:436-443.

40. Geleijnse JM, Giltay EJ, Grobbee DE, et al: Blood pressure response to fish oil supplementation: metaregression analysis of randomized trials. J Hypertens 2002, 20:1493-1499.

doi:10.1186/1476-511X-11-104

Cite this article as: Haug et al: Increased EPA levels in serum phospholipids of humans after four weeks daily ingestion of one portion chicken fed linseed and rapeseed oil. Lipids in Health and Disease 2012 11:104.

\section{Submit your next manuscript to BioMed Central and take full advantage of:}

- Convenient online submission

- Thorough peer review

- No space constraints or color figure charges

- Immediate publication on acceptance

- Inclusion in PubMed, CAS, Scopus and Google Scholar

- Research which is freely available for redistribution 